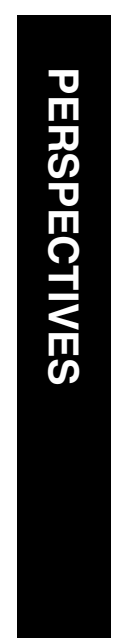

\section{ReGAE 2: glaucoma awareness and the primary eye-care service: some perceptions among African Caribbeans in Birmingham UK}

V Cross, P Shah, R Bativala and P Spurgeon
Birmingham and Midland Eye Centre, City Hospital NHS Trust, Birmingham, UK

Correspondence: P Shah, Birmingham and Midland Eye Centre, City Hospital NHS Trust, Dudley Road, Birmingham B18 7QU, UK Tel: + 441215543801 ; Fax: + 441214763620 . E-mail: p.f.shah@talk21.com

Received: 14 April 2005 Accepted in revised form: 24 February 2006 Published online: 11 August 2006

\begin{abstract}
Aims Investigations into glaucoma awareness have drawn on informed, clinicbased populations. The paper reports a section of findings from a larger study that aimed to elicit the perceptions of those potentially less informed in community settings.

Methods A qualitative investigation used face-to-face interviews and focus group discussions with 48 African Caribbean participants outside the hospital eye-service. Interview data were transcribed and coded using manual and computer-aided methods. Inferences and interpretations were corroborated by discussion with expert advisors and community members not directly involved in the study. Results Positive attitudes to health promotion existed, but 'eye health' did not appear to be integral to individuals' health schemas. The capacity for primary eye care to enhance glaucoma knowledge appeared under utilised and inconsistent across modes of service delivery and was undermined by perceived conflicts of interest. Conclusions Enhancing reciprocal understanding between service users and ophthalmic practitioners in primary care is central to developing flexible, responsive local eye-care services. The study suggested useful foci for cultural self-reflection and selfawareness on the part of health professionals themselves, in relation to glaucoma detection. Areas for further research are identified.
\end{abstract} Eye (2007) 21, 912-920; doi:10.1038/sj.eye.6702461; published online 11 August 2006

Keywords: glaucoma; primary eye-care; AfricanCaribbean; UK
Introduction

Adult onset primary open angle glaucoma (POAG) is a major cause of irreversible blindness in Black people. People of AfricanCaribbean descent are up to eight times more likely to develop POAG, which appears 10-15 years earlier than in other ethnic groups. ${ }^{1-3}$ Patients with glaucomatous visual loss at the start of treatment are significantly more likely to become blind, and African-Caribbean patients in the UK are 4.5 times more likely to present late than their White counterparts. ${ }^{4,5}$ In most patients with POAG the disease is asymptomatic until it has reached an advanced stage. However, blindness is avoidable with early detection and treatment. To detect early glaucomatous disease it is necessary to case-find asymptomatic patients in the target population. Ophthalmic professionals are concerned that lack of awareness of risk, low levels of referral, and under utilisation of the primary eye-care service (PECS) mean that unnecessary numbers of Black people will continue to become blind as a result of POAG. ${ }^{1,4,5}$ Investigations into glaucoma awareness and barriers to access, have drawn predominantly on informed, clinicbased populations, but there is a need to explore perceptions of those at risk, and potentially less informed, outside the hospital eye-service (HES) in a community-based setting.

Research into glaucoma and ethnicity: the Birmingham project

The Birmingham Research into Glaucoma and Ethnicity (ReGAE) Project is a UK-based programme of qualitative and quantitative glaucoma research aimed at contributing to 
unraveling the complexity of African-Caribbean and other glaucomas. It comprises several phases addressing issues related to sociocultural influences on glaucomarelated health behaviours, POAG pathogenesis, and clinical outcomes. This paper reports some early findings from the first qualitative investigation of the programme. These relate specifically to PECS utilisation among African-Caribbean people from four inner city wards of Birmingham UK. Further findings from the wider investigation are reported elsewhere. ${ }^{6,7}$

\section{Aims}

In the UK, approximately $80 \%$ of glaucoma referrals to the HES originate from routine sight tests by optometrists in primary care. ${ }^{8}$ Optometrists are central to the process of enhanced glaucoma detection and management. Thus, the aims of this part of the investigation were to

- identify issues related to utilisation of the PECS by African-Caribbean people;

- consider the implications for enhancing the role of the PECS in glaucoma detection and management.

\section{Materials and methods}

A semistructured interview guide was developed, which included a family tree to indicate near relatives who had vision-related conditions. The findings reported below relate to three specific foci within the guide: access route to the optometrist, reasons for visiting the optometrist, and experiential accounts of optometric visits.

Potential study participants were accessed through key informants who acted as channels of introduction to individuals who fitted the study criteria. A range of local organisations was approached by telephone or in writing. If an initial approach failed to elicit a response, one further attempt was made. In all 12 organisations were approached, of which ten responded. That is, participants were recruited for their ability and willingness to recount relevant experiences and viewpoints (purposive sampling), and their availability (convenience sampling). The recruitment process involved a combination of the following:

- an initial meeting with a key informant to outline the background and objectives of the study;

- subsequent introductions to specific individuals who were then invited to take part;

- presentations about the study at churches, colleges, or group meetings, followed by invitations to take part;

- authorisation to approach individuals under the auspices of an organisation.
In total, 48 participants were interviewed. In all, 28 individual interviews were recorded (with permission). Two focus groups were also recorded (with permission) to gain specific perspectives on some emergent issues. Focus Group 1 elicited an all male perspective from six men between 34 and 43 years. Focus Group 2 comprised 13 members of a local diabetic support group. All interviews lasted approximately $1 \mathrm{~h}$. A university-based researcher of African-Caribbean background (VC) conducted all the interviews. They occurred at various times and locations determined by what was most convenient and acceptable for participants. Throughout the interviews the generic term 'glaucoma' was used in preference to POAG. In lay usage little distinction is made between the terms 'optometrist' and 'optician'. Both terms were used interchangeably, to describe primary eye-care practitioners accessed by participants.

\section{Characteristics of the participants}

In total 48 people (female $=24$, male $=24$ ) were interviewed. The age range was 60 years: mean $=48$, median $=42$, interquartile range $=35$. Participants identified their place of birth and described their ethnicity, using the list of descriptors included in the 2001 UK census (Figures 1 and 2). The majority of those born in the UK traced their roots back to Jamaica but St Kitts, Nevis, and Barbados were also represented. All the participants in this study identified with the terms 'Black' and 'African-Caribbean' and used them interchangeably during interviews.

\section{Coding and interpretation of interview data}

In relation to PECS utilisation the interviews focused on three key areas: access route to the optometrist, causal stimulus for an optometric visit, and experiential accounts of the optometric encounter. All interviews were fully transcribed and coded using both manual and computer-aided methods $\left(\mathrm{NVivo}^{\odot}\right.$ software programme

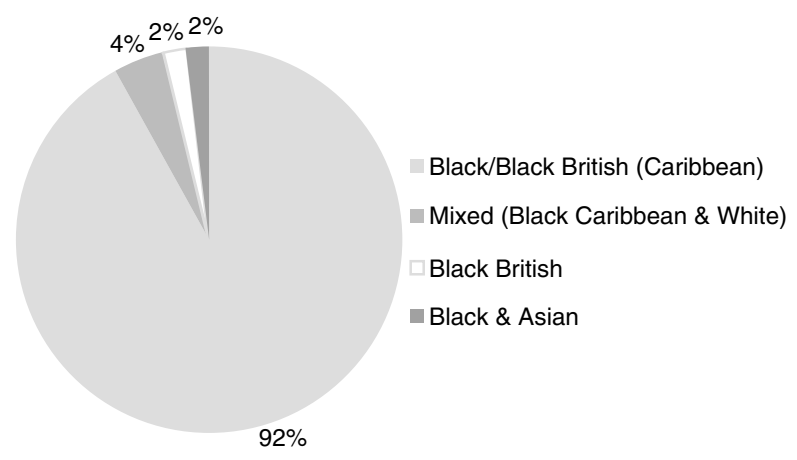

Figure 1 Participants' self-determined ethnicity $(n=48)$. 

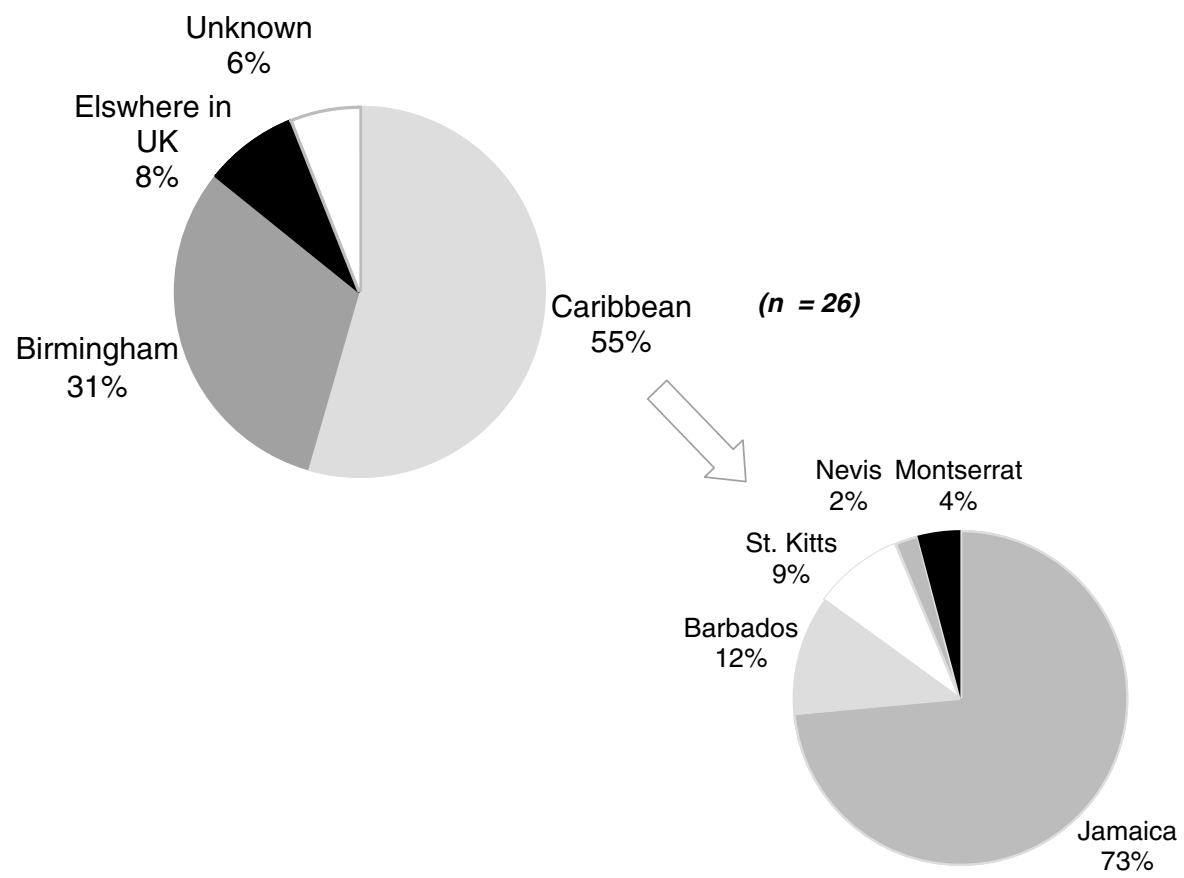

Figure 2 Participants' place of birth $(n=48)$.

for qualitative data management). Interpretation and inferences were validated through discussion of emerging concepts within the research team, checking back with some participants, independent analysis of randomly selected transcripts, discussion with expert advisors and other members of the African-Caribbean community not directly involved in the study. Emergent themes were identified and clustered into categories as described in subsequent sections below.

\section{Findings of the research}

A number of themes emerged from the interview data. These are identified in Table 1 alongside illustrative interview extracts. Extracts are annotated with the interview number, gender and age, for example 20:M38. Focus groups are prefixed by 'G' (G2: M61). Interviewer's words are italicised and clarifications appear in square brackets. Speech data are coded as follows: - indicates a pause; indicates speaker's emphasis; (...) indicates interrupted speech; ... indicates words or phrases from the transcript omitted. In all, $67 \%$ of participants $(n=32)$ said they had heard of glaucoma before taking part. Knowledge derived mostly from family experience. Of the participants, $79 \%$ had undergone an eye examination in adult life. However, less than $25 \%$ of participants who had heard about glaucoma said they had acquired the information from their optometrist. Descriptions of glaucoma varied for example, 'weakness in the eye', 'blurry vision', 'something to do with skin over the eyes'. The most detailed descriptions such as 'a build up of pressure due to lack of drainage', came from participants who had heard of the condition from an optometrist.

\section{Access routes to the optometrist}

Access routes to the PECS varied from direct self-referral to indirect referral via the general practitioner (GP). While for some with eye health concerns the optometrist was the logical first port of call, for others, self-referral was not perceived to be an option.

I believe I have to go to the doctor, for the doctor to send me to see the eye optician (10:F44).

... first of all I'd go to my GP and then take it from there... see if he'd send me to the optician's or the hospital, or the eye hospital or whatever (20:M38).

\section{Reasons for optometric visits}

Although their attitudes to health in general reflected a 'health promotion perspective ${ }^{\prime 9}$ for example, healthy eating habits, using the gym, eye health was not integral to participants' schema of preventive health behaviour. Eyes were not seen as 'part of health'. An optometric visit was usually symptom driven, sometimes after an illness visit to the GP or secondary to some other diagnosis such as diabetes. Among the $72 \%$ of those who had had at least one eye test performed in their adult life, reasons for 
Table 1 Themes and illustrative extracts from individual interviews and focus groups

\begin{tabular}{|c|c|c|c|c|c|}
\hline \multirow{2}{*}{$\begin{array}{l}\text { Interview focus } \\
\text { Causal stimuli for } \\
\text { visit to optometrist }\end{array}$} & \multirow{2}{*}{$\begin{array}{l}\text { Emergent themes } \\
\text { Symptoms work } \\
\text { family }\end{array}$} & \multicolumn{4}{|c|}{ Interview extracts } \\
\hline & & $\begin{array}{l}\text { 'I was at college...the glasses } \\
\text { made a big difference and } \\
\text { now I can see the world like } \\
\text { everyone else... If I didn't } \\
\text { have those headaches I would } \\
\text { never have gone to the } \\
\text { opticians' G1:M43. }\end{array}$ & $\begin{array}{l}\text { '....it was only when I worked } \\
\text { at the age of } 20 \text {, doing } \\
\text { repeated computer } \\
\text { work... getting headaches. } \\
\text { They said 'yeah your left eye } \\
\text { is very weak and should have } \\
\text { been spotted (in childhood)' } \\
\text { G1:M39. }\end{array}$ & $\begin{array}{l}\text { 'Well, to be honest, up until } \\
\text { I was diagnosed diabetic [18 } \\
\text { months ago] I think I went for } \\
\text { an eye test about } 10 \text { years ago } \\
\text { (applying to the fire service)' } \\
\text { 20:M38. }\end{array}$ & $\begin{array}{l}\text { '... my son was complaining } \\
\text { about his eyes. I said to myself } \\
\text { 'I've not had my eyes tested } \\
\text { for donkey's, let me make an } \\
\text { appointment for both of us' } \\
\text { 19:F42. }\end{array}$ \\
\hline \multirow[t]{4}{*}{$\begin{array}{l}\text { Access route to } \\
\text { optometrist }\end{array}$} & Indirect & $\begin{array}{l}\text { 'I thought I had to go to the } \\
\text { doctor first...I just see this } \\
\text { woman about glasses and } \\
\text { she said }\end{array}$ & $\begin{array}{l}\text { 'First of all I'd go to my GP } \\
\text { and then take it from } \\
\text { there... see if he'd send me } \\
\text { to the optician's or the eye } \\
\text { hospital, or whatever' 20:M38. }\end{array}$ & $\begin{array}{l}\text { 'My GP he's got to send me to } \\
\text { the optician to test me eyes. } \\
\text { He don't want nothing to do } \\
\text { with me eyes' G2:M72. }\end{array}$ & $\begin{array}{l}\text { 'I was doing a course...I felt I } \\
\text { was getting really dizzy. I just } \\
\text { thought I was getting a bit } \\
\text { short-sighted. So (the optician) } \\
\text { was the first contact I thought } \\
\text { of' } 32 \text { :F36. }\end{array}$ \\
\hline & Direct & $\begin{array}{l}\text { I couldn't go there unless the } \\
\text { doctor send you' } 10: F 44 \text {. }\end{array}$ & & & \\
\hline & \multirow[t]{2}{*}{ Potential costs } & $\begin{array}{l}\text { 'I always think paying for } \\
\text { frames and lenses separately } \\
\text { is a rip off. }\end{array}$ & $\begin{array}{l}\text { 'When you are blind you have } \\
\text { no job. So money doesn't } \\
\text { count then. So then you spend } \\
\text { the money first and save } \\
\text { blindness. }\end{array}$ & $\begin{array}{l}\text { 'If you have to pay, you have } \\
\text { to pay'. 15:M38 }\end{array}$ & \multirow[t]{2}{*}{$\begin{array}{l}\text { 'My mother's got } \\
\text { glaucoma...I found you could } \\
\text { get a free eye test... so I } \\
\text { went... a few years back, and } \\
\text { the age they told me was like, } \\
\text { way into the future' G2:M40. }\end{array}$} \\
\hline & & $\begin{array}{l}\text { And that is what deters me } \\
\text { from going for tests more } \\
\text { frequently...my eyes are the } \\
\text { aspect of my health I take least } \\
\text { seriously' } 21: F 30 .\end{array}$ & $\begin{array}{l}\text { We are not doing that! We are } \\
\text { frightened of spending money } \\
\text { on our health' G2:61. }\end{array}$ & $\begin{array}{l}\text { 'It's a service that's being } \\
\text { provided by somebody' } \\
\text { 19:F42 }\end{array}$ & \\
\hline \multirow[t]{3}{*}{$\begin{array}{l}\text { Experiential } \\
\text { accounts of } \\
\text { optometric } \\
\text { encounters }\end{array}$} & \multirow[t]{3}{*}{ Information giving } & $\begin{array}{l}\text { 'It scares me this } \\
\text { glaucoma... if it happens will } \\
\text { I go blind, you know'? }\end{array}$ & $\begin{array}{l}\text { 'But when you go for tests } \\
\text { they say you need glasses and } \\
\text { I'm thinking, 'Hold on, } \\
\text { why's that'? }\end{array}$ & \multirow[t]{3}{*}{$\begin{array}{l}\text { 'Yeah and checking the back } \\
\text { of my eyeball or whatever. } \\
\text { I don't know what she's } \\
\text { looking for, but she's checking } \\
\text { it for my eye health, making } \\
\text { sure your OK'. 16:F43 }\end{array}$} & $\begin{array}{l}\text { 'I think it was the full works } \\
\text { I had, and also for the } \\
\text { glaucoma. I think he dropped } \\
\text { things in my eyes...the } \\
\text { pressure's quite good. }\end{array}$ \\
\hline & & $\begin{array}{l}\text { Do you discuss this with the } \\
\text { optician? }\end{array}$ & $\begin{array}{l}\text { The thing is, I can see } \\
\text { perfectly, I don't see a } \\
\text { problem, but they find } \\
\text { the problem' 3:F42. }\end{array}$ & & $\begin{array}{l}\text { It was } 10 \text { or } 11 \text {, which is very } \\
\text { good he says' } 21: F 30 .\end{array}$ \\
\hline & & $\begin{array}{l}\text { There's no opportunity He } \\
\text { seems more interested in } \\
\text { selling me glasses' 4:F51. }\end{array}$ & & & \\
\hline
\end{tabular}


seeking a test included the presence of visual symptoms such as blurring, dizziness, photophobia, and headaches.

I just thought I was getting a bit short-sighted, so I thought I'd get my eyes tested to see if I needed any glasses (32: F36).

Although it seems reasonable to expect myopes to have more contact with primary eye-care and hence be more likely to be informed about glaucoma, for some participants this would be a misguided assumption. One participant talked of how, at the age of 7 years, he had difficulty seeing the board throughout his school life and always sat at the front. Aged 18 years he developed headaches and was directed to the optometrist by his GP. He described the impact of acquiring spectacles for the first time.

I remember the first morning I put on my specs. I could see the bus coming from a mile! I could see what number it was...I was at college at the time and I went through that part of my life not really knowing that I needed glasses... the glasses made a big difference and now I can see the world like everyone else is seeing it. And if I didn't have those headaches I would never have gone to the optician's. I'd still be thinking, you know, the world's a blur! (G1:M43).

For another the consequences of acknowledging the problem (spectacles) were considered unacceptable. $\mathrm{He}$ described how he had cheated in a school eye test by pretending to cover his stronger eye when reading the Snellen chart.

... and it was only when I worked at the age of about 20, just doing repeated computer work, repeatedly getting headaches. So I went to one of these (drop-in) opticians and they said 'Yeah, your left eye is very weak and should have been spotted in the first, sort of, 5-8 years of your life. But it wasn't and I know why it wasn't! (laughs) (G1:M39).

Employment requirements, sporting activities and having a child with eye problems also played a part in seeking an eye examination (Table 1).

\section{Experiential accounts}

Potential costs

Participants' feelings about the experience of visiting an optometrist varied from very positive to very negative. Feeling pressured by the potential cost implications of a visit was a theme in the most negative responses. Studies have shown that eye test charges can be a deterrent to using PECS and this was explored in the interviews. Of 
all participants, 59\% knew that there was a charge, but only a minority knew roughly how much it might be. Estimates ranged from 10 to $£ 30$. Some people were sanguine about the charge, commenting that if you have to pay, you have to pay' (15:M38), and '...it's a service that's being provided by somebody' (19: F43). In all, 29\% felt that eye test charges did or would deter people from visiting the optometrist. It was generally agreed that some people could not afford to pay. However, there were those who considered the issue was mainly one of choice about how to spend money, rather than inability to pay.

When you are blind you have no job. So money doesn't count then. So then you spend money first and save blindness. We are not doing that! We are frightened of spending money on our health G2: M61.

Views in either case were not associated with any particular socioeconomic status. Most thought they knew whether they would be exempt from charges, including all those who were diabetic. One participant who had expected to be exempt because his mother had glaucoma, was surprised to find when he went for a test, that this was not the case because he was under 40 years of age (Table 1).

The cost of spectacles played a part in acceptance of suboptimal vision and delay in deciding to change spectacles when necessary. So for example, spectacles being damaged or becoming unfashionable rather than deteriorating vision became triggers for attendance at the optometrist.

I always think paying for your glasses, frames ...paying for the frames and the separate lenses, separately is a rip off. It is really expensive I think, glasses. And that is usually what deters me from going for tests and things more frequently...my eyes are the aspect of my health that I take least seriously (21: F30).

\section{Information giving}

Lack of information giving by optometrists was a further cause of dissatisfaction. At the same time, awareness and anxieties about glaucoma risk were not necessarily a stimulus for regular attenders to seek information from their optometrist during a consultation.

I definitely should be doing more, definitely. But you know what amazes me? I can see perfectly, fine. But when you go for the eye tests they say you need glasses and I'm thinking, 'Hold on, why's that?' The thing is, I can see perfectly, I don't see a problem, but they find the problem ( $3:$ F51). ...it scares me with this glaucoma thing because you don't know when its gonna come, what causes it, and if it happens will I go blind gradually, you know?

Do you discuss these issues when you go to the optician?

... the opportunity doesn't present itself really. He just gets on with what he needs to do. We talk about my glasses really. He seems to be more interested in selling me new ones (4:F51) [Mother has glaucoma].

Positive experiences were associated with information giving, but further exploration revealed this was sometimes limited in extent. Of those who had had an eye test, not all were aware that this had included some aspects of glaucoma testing, such as tonometry and examination of optic nerve heads, although it was apparent from their descriptions of the procedure that these had occurred. For example, 'Yeah, and checking the back of my eyeball or whatever. I don't know what she's looking for, but she's checking it for my eye health, you know, making sure you're OK', (16: F43). In contrast, another participant described feeling reassured on being told that her intraocular pressure was normal.

I think it was the full works I had, and also for the glaucoma. I think he dropped things in my eyes, then I had to read... because the pressure's quite good ... because my pressure's either 10 or 11 and it goes up to 20 does it? Which is very good he says (?).

\section{Delivery mode}

Experiential accounts also included some marked contrasts in people's preference for particular modes of service delivery, influenced by speed and convenience as well as information giving. For some, the speed and convenience of drop-in, express type delivery was preferred. For others, thoroughness of eye examination and extent of information giving offset the more protracted appointment system of the independent optometrist or conventional high street chain. In general, younger participants preferred the former, while those in $30+$ age groups preferred the latter.

I went to one of those, I call them 'conveyer belt opticians' and the service was awful. You felt like a commodity. And it was so quick. It was unbelievable. So I went back to my regular (independent) optician (19: F42).

....the (express-type) eye check, it was a very quick one. This independent guy, he seems to take more time....so I always leave with a clear understanding of whether my eyes have improved or got worse and why, and what he's doing with the 
prescription to help (G2:M39).

it would be like, passing (branch of high street chain) and thinking 'Go on, I've got five minutes, let me pop in and see what they say...

And if you had to make an appointment?

I wouldn't go back for the appointment (G2:M41).

\section{Discussion}

Inevitably these findings are attached to the viewpoints of the particular individuals and groups who took part. However, themes emerged that firstly, could inform development of an enhanced role for the PECS in detection of POAG in African Caribbeans, and glaucoma management in general; secondly, facilitate participation in subsequent community-based glaucoma research. In Figure 3 these themes clustered into four categories relating to participants' knowledge and understanding, their eye health behaviour, professional conflicts of interest, and communication. Each is linked to particular service issues, which impact upon primary eye-care utilisation and ultimately, access to the HES.

Access to health care involves the ease with which people obtain necessary services in a timely manner and in the most appropriate environment. For those at risk of POAG this means before the disease becomes symptomatic and in a setting that provides a specific subset of clinical skills. In theory, access is a supply issue associated with both the system and providers themselves (Table 1). In practice, the extent to which 'potential access' translates into 'realised access' and hence observed utilisation, may depend as much on the predilections and prejudices of individual consumers (demand-side issues) as on barriers to access. ${ }^{9-11}$ Thus, access and utilisation are closely interrelated, making it difficult to disentangle the evidence for any discrepancies and identify a focus for reflection on practice.

\section{Consumer-based issues}

POAG frequency tends to be higher in males ${ }^{12}$ and an association with myopia has been observed. ${ }^{13,14}$

However, the study demonstrates that any assumption that myopes will be better informed about glaucoma by virtue of contact with the service could be misguided. Normalisation of impaired visual acuity, by disguising or minimising symptoms suggests PECS utilisation rates may not reflect the level of need, and this, combined with low levels of glaucoma awareness, presents a demandside barrier to primary eye-care utilisation. At-risk messages are frequently accompanied by a diagnostic invitation - 'the 'gift' of knowing'15 in the belief that individuals will be empowered to make informed decisions about accessing services. However, degree of empowerment depends on how well the health-care system is explained and understood as well as on service providers themselves. Such uncertainty could mean that enacting the 'at-risk' role by taking the initiative to avoid becoming 'ill' is made more difficult for some individuals. It could also contribute to low self-efficacy in responding to glaucoma-related health messages.

The role of social networks in exchanging information and advice about the best way to respond to health concerns is influential. ${ }^{16}$ Enhancing satisfaction with the PECS by paying attention to choice of providers, optimising practitioners' communication skills and increasing consistency of information would all help to foster trust, and encourage community members to advocate for appropriate changes in eye-health behaviour. As a result receptivity to glaucoma-related messages could be enhanced among those at most risk.

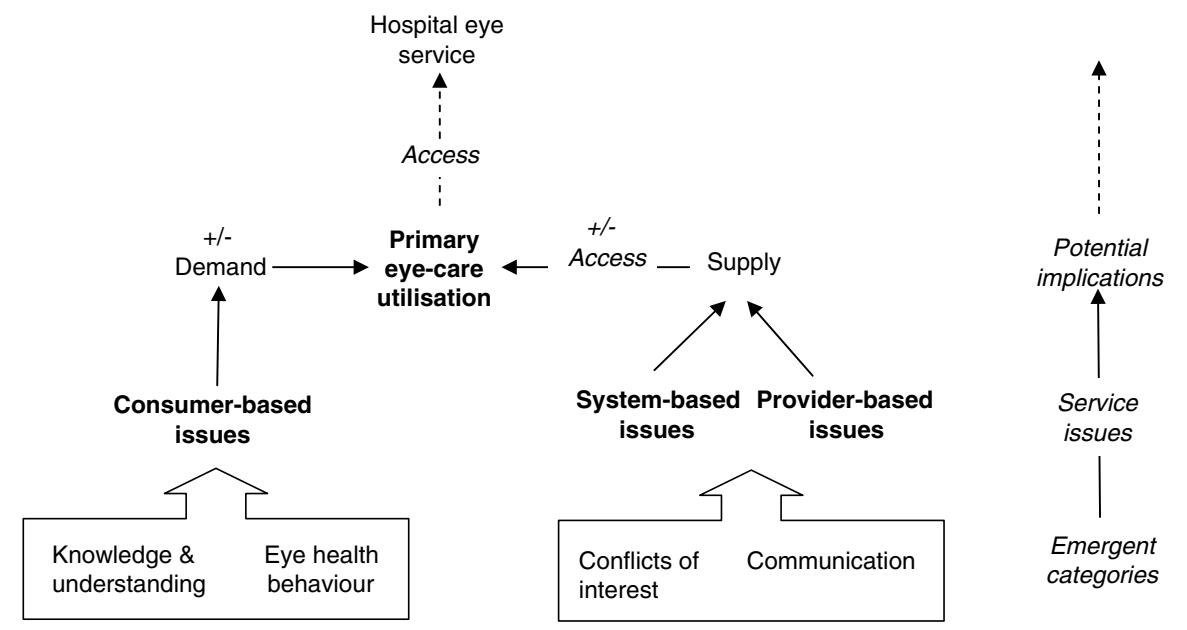

Figure 3 Thematic categories emerging from interviews and their implications for PECS utilisation. 


\section{System-based issues}

The interviews also revealed supply-side barriers to access. Optometrists, of necessity, are engaged in a commercial as well as a diagnostic enterprise. This has an inevitable impact on realised access. Financial constraints will limit some people's ability to pay for routine eye examinations, ${ }^{17}$ and the additional cost of spectacle frames and lenses may also present a further barrier. There are obvious implications inherent in PECS charges for the self-efficacy of those experiencing deprivation and on low incomes, in responding to glaucoma-related health education messages. At the same time, potentially, they could undermine trust in the care giving relationship. Trust inheres in both individual care providers and health care systems. ${ }^{18,19}$ As well as truth telling, dimensions of trust include, fidelity, honesty, and competence. ${ }^{20}$ Fidelity and honesty involve disclosing conflicts of interest, a theme emergent from participants' descriptions of wider health care encounters. The potential impact of such perceptions on service utilisation and message receptivity emphasises the importance of disassociating the commercial role of optometrists in primary care from their crucial role in glaucoma case detection.

\section{Provider-based issues}

Most patients have difficulty assessing competence directly, so their views of competence are heavily influenced by a (practitioner's) interpersonal competence-communication skills and bedside manner (Hall et al 2001, page 621). ${ }^{20}$

Insofar as the competence dimension of trust refers to communication skills that enhance technical aspects of care, trust in health professionals has been shown to correlate strongly with patient satisfaction. It is associated with treatment adherence, practitioner loyalty, not seeking second opinions, recommendations to others, and perceived effectiveness of care. ${ }^{18-20}$

Participants' comments reflected the 'competence dimension' of trust. Ophthalmologists in the HES have been shown to be more optimistic about patients' levels of knowledge and understanding following a consultation than is actually reported by patients themselves. ${ }^{21}$ Whether such discrepancies exist in the PECS would be worth exploring. Are optometrists aware of making decisions about the amount of information they give and to whom? On what basis do they decide?

\section{Limitations and further research}

It was a limitation of this study that only $31 \%$ of participants occupied National Statistics socioeconomic classes $6-8$, compared to $12 \%$ in classes $3-5,27 \%$ in class 2 and $2 \%$ in class 1.2 . The study's findings regarding barriers to access and self efficacy in utilising the PECS raise the possibility that at risk individuals in less advantaged groups could be lost to the system. Although it proved difficult to achieve for this study, a systematic attempt to elicit their viewpoints is indicated.

Enhancing the performance of the PECS as a means of glaucoma case detection, and as a conduit to the HES for appropriate individuals, is predicated on a HES able to respond effectively. As the face and voice of glaucoma, POAG patients have an important role to play as credible purveyors of glaucoma-related health education messages. Efforts to achieve effective reciprocity between primary and hospital eye-care services at local policy level will benefit by being informed by HES users' perspectives and viewpoints on such issues as patient satisfaction and shared care in relation to glaucoma. These are important areas for further research.

\section{Conclusion}

This study was part of a larger investigation designed to build on existing qualitative research on glaucoma, by focusing specifically on the perceptions of AfricanCaribbean people in a primary care-based setting outside the HES. Clearly, it is important not to use such a local qualitative investigation to make general statements about the response of African-Caribbean people to POAG risk, or their attitude towards the PECS. Shifting the reference points for intervention from the imperatives and perspectives of providers, to those of service users demands a degree of cultural self-reflection and selfawareness on the part of health professionals themselves. This study has identified several foci for such reflection in relation to glaucoma detection. Further research in these areas, using a combination of qualitative and survey methods, is indicated, to help ensure continuing professional development in the PECS remains congruent with developments in user education and expectations.

\section{Acknowledgements}

We thank the individuals and organisations who gave up their time to facilitate and participate in the study described in this paper. VC designed and carried out the qualitative research study, and was involved at every stage of preparation and presentation of this paper. PS conceived and is leader of the Birmingham ReGAE Project, and contributed extensively to the preparation and presentation of this paper. RB and PSp also contributed to preparation of this paper. PS is the guarantor. The following organizations funded the 
research: Birmingham Strategic Health Authority, Heart of Birmingham Teaching Primary Care Trust, City Hospital NHS Trust, Pfizer UK, and Birmingham Social Services.

\section{Ethical approval:}

The qualitative research study described in this paper was approved by the Local Research Ethics Committee based at City Hospital NHS Trust, Dudley Road, Birmingham, B18 7QH.

\section{References}

1 Racette L, Wilson MR, Zangwill LM, Weinreb RN, Sample PA. Primary open-angle glaucoma in blacks: a review. Survey Ophthalmol 2003; 48(3): 295-313.

2 Chen PP. Blindness in patients with treated open-angle glaucoma. Ophthalmology 2003; 110(4): 726-733.

3 Hattenhauer MG, Johnson HH, Ing HH, Herman DC, Hodge DO, Yawn BP et al. The probability of blindness from open-angle glaucoma. Ophthalmology 1998; 105: 2099-2104.

4 Fraser S, Bunce C, Wormald R. Retrospective analysis of risk factors for late presentation of chronic glaucoma. $\mathrm{Br} J$ Ophthalmol 1999; 83(1): 24-28.

5 Wormald R, Basuri E, Wright L, Evans J. The African caribbean eye survey: risk factors for glaucoma in a sample of African Caribbean people living in London. Eye 1994; 8(3): 315-320.

6 Cross V, Shah P, Bativala R, Spurgeon P. ReGAE 3: glaucoma awareness and perceptions of risk among AfricanCaribbeans in Birmingham UK. Diversity in Health and Social Care 2005; 2(2): 81-90.

7 Shah P, Cross V. ReGAE 1: The Shah-Cross Model as an orientating framework in African-Caribbean glaucoma awareness research. Eye: 2006; advance online publication, 27 January 2006; doi:10.1038/sj.eye.6702130.

8 Vernon SA, Ghosh G. Do locally agreed guidelines for optometrists concerning the referral of glaucoma suspects influence referral practice? Eye 2001; 15(Part 4): 458-463 August

9 Goddard M, Smith P. Equity of access to health care services: Theory and evidence from the UK. Soc Sci Med 2001; 53: 1149-1162.

10 Aday LA, Anderson RM. Equity of access to medical care: a conceptual and empirical overview. Med Care 1981; 19: 4-27.

11 Stainton Rogers W. Explaining Health and Illness. An Exploration of Diversity. Harvester Wheatsheaf: London, 1991.

12 Leske MC, Nemesure B, He Q, Wu S-Y, Hejtmancik J, Hennis A. Patterns of open-angle glaucoma in the Barbados Family Study. Ophthalmology 2001; 108(6): 1015-1022.

13 Mitchell P, Hourihan F, Sandbach J, Wang JJ. The relationship between glaucoma and myopia: the Blue Mountains Eye Study. Ophthalmology 1999; 106: 2010-2015.

14 Wu S-Y, Nemesure B, Leske MC. Refractive errors in a black population: the Barbados eye study. Invest Ophthalmol Vis Sci 1999; 40: 2179-2184.

15 Kenen RH. The at-risk health status and technology: a diagnostic invitation and the 'gift' of knowing. Soc Sci Med 1996; 42(11): 1545-1553.

16 Emmons KM. Health behaviours in a social context. In: Berkman LF, Kawachi I (eds) Social Epidemiology. Oxford University Press: Oxford, Chapter 11; 2000.

17 Laidlaw DSH, Bloom PA, Hughes AO, Sparrow JM, Marmion VJ. The sight test fee: effect on ophthalmology referrals and rate of glaucoma detection. BMJ 1994; 309: 634-636.

18 Wilson S, Morse JM, Penrod J. Developing reciprocal trust in the care giving relationship. Qual Health Res 1998; 8(4): 446-465.

19 Mechanic D. Changing medical organization and the erosion of trust. Millbank Quart 1996; 74: 171-189.

20 Hall MA, Dugan E, Zheng B, Mishra WK. Trust in physicians and medical institutions: what is it, can it be measured, and does it matter? The Millbank Quart 2001; 79(4): 613-639.

21 Killebrew B, Corn AL. An initial study of ophthalmologistparent communication during first office visits. RE:view, Rehabil Educ Blin Visual Impair 2002; 34(4): 135-142. 